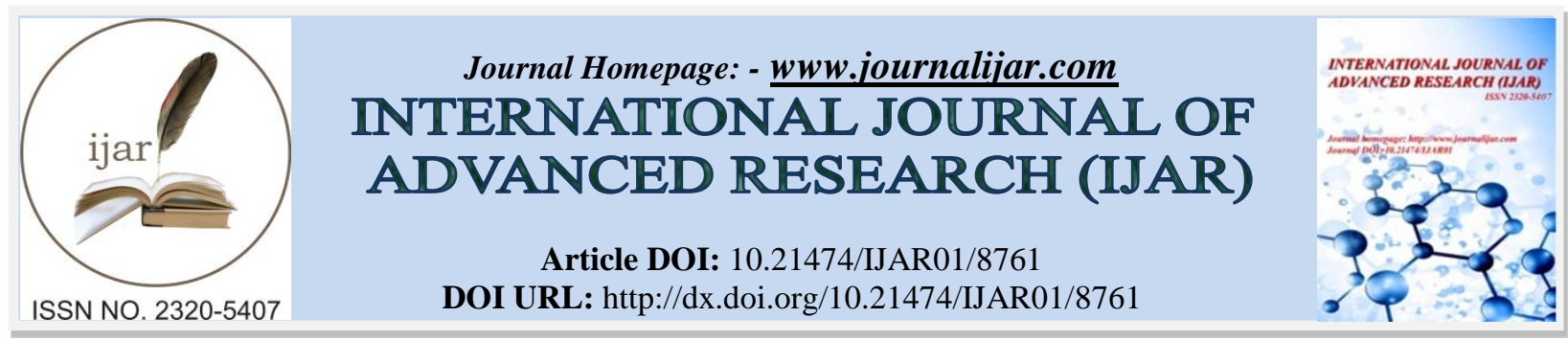

RESEARCH ARTICLE

\title{
OPTIMIZATION OF IN VITRO ADVENTITIOUS SHOOT INDUCTION IN JATROPHA CURCAS BY RESPONSE SURFACE METHODOLOGY.
}

\section{Herrera-Cool Gilbert José ${ }^{1}$, Rodríguez-Buenfil Ingrid Mayanin ${ }^{1}$, Iglesias-Andreu Lourdes Georgina ${ }^{2}$ and Lopez-Puc Guadalupe'.}

1. Centro de Investigación y Asistencia en Tecnología y Diseño del Estado de Jalisco, A.C., Sede Sureste, Carretera Sierra Papacal-Chuburna Puerto Km. 5, 97302 Sierra Papacal, Merida, Yucatan, Mexico.

2. Instituto de Biotecnología y Ecología. Universidad Veracruzana, Campus para la Cultura, las Artes y el Deporte, 91001 Xalapa, Veracruz, México.

\section{Manuscript Info}

Manuscript History

Received: 20 January 2019

Final Accepted: 22 February 2019

Published: March 2019

Key words:-

optimization, response surface methodology, in vitro, Jatropha curcas, central composite design.

\section{Abstract}

Jatropha curcas is a second generation biofuel crop that is also an important biological resource. Meeting increasing biofuel demand requires wider cultivation of specialized varieties, highlighting the need for massive culture techniques such as in vitro micropropagation. Key stages in plant tissue culture processes, such as adventitious shoot induction, can be optimized to increase micropropagation protocol efficiency. Response surface methodology, a statistical tool for this purpose, was applied to optimize in vitro induction of adventitious shoots in the J. curcas micropropagation process. A preliminary assay was done in which 6-( $\gamma, \gamma$-dimethylallylamino) purine and indolacetic acid were selected as the factors to optimize. A $2^{2}$ central composite design with four central points was then applied to fit it to a second grade model and a rotatable design applied to produce the final model and surface graphics. Focused on maximum point, the surface model design identified maximum adventitious shoot induction to be 21 shoots per explant in Murashige and Skoog medium at $75 \%$ ionic strength and containing $83.3 \mu \mathrm{M}$ 6-( $\gamma, \gamma$-dimethylallylamino) purine and $1.3 \mu \mathrm{M}$ indolacetic acid. This is the first report in which response surface methodology was found to be an effective statistical technique for optimizing adventitious shoot induction in Jatropha curcas.

Copy Right, IJAR, 2019,. All rights reserved.

\section{Introduction:-}

A member of the Euphorbiaceae plant family, Jatropha curcas is native to Mexico and Central America (Navarro et al., 2016). Its seeds can contain up to $40 \%$ oil which has made it a preferred source for producing biodiesel by transesterification (Li et al., 2016; Soares et al., 2016). Increasing demand for biodiesel has driven efforts to expand its cultivation. Asexual propagation through stakes and sexual propagation through seeds have been used to broaden cultivation, although production remains challenging due to the species low drought resistance, disease susceptibility and weak radicular system (Sujatha et al., 2005; Datta et al., 2007). Growing demand for J. curcas genetic material has led to use of massive plant multiplication techniques (Panghal et al., 2012). In vitro plant tissue culture of $J$. curcas has been studied and shown to be viable for adventitious shoot induction by indirect organogenesis,

Corresponding Author:- Guadalupe Lopez-Puc. 
producing up to thirteen shoots per explant (Liu et al., 2016). There are other reports of adventitious shoot morphogenesis producing seven, six and eleven shoots from petiole, stem and leaf explants, respectively (Verma and Verma, 2015). In other studies, direct organogenesis of petiole resulted in seven adventitious shoots (Liu et al., 2015), and mature leaves produced up to 2.98 shoots per explant (Zhang et al., 2013).

Plant growth regulators (PGR) are vital to developing an efficient micropropagation protocol. The PGR 6- $\gamma, \gamma-$ dimethylallylamino) purine (2ip) cytokinin is involved in regulation of cell proliferation, cell cycle progression and division (Werner et al., 2003); shoot growth and root growth inhibition (Miller et al., 1956); and developmental processes in plants, including organ formation, leaf senescence, shoot meristem formation and maintenance (Monk, 1994). Another PGR used in combination with cytokinin for in vitro development of adventitious shoots is indolacetic acid (IAA) auxin, an indispensable phytohormone that regulates many aspects of plant development. It has been implicated in embryonic and post-embryonic development, tropisms such as movement in relation to light and gravity, and it influences aspects of cell division, cell elongation and cell differentiation (Teale et al., 2006).

Auxin and cytokinin are important to producing cellular response in plant tissue culture. However, achieving the most efficient cellular response in a single or multiple-step micropropagation protocol requires an extensive preliminary experimental process to identify the most appropriate conditions considering the possible interactions that can occur between different factors. Statistical tools are crucial in this stage. These can include preliminary assays, factorial designs and surface response methodology (SRM) (Anderson and Whitcomb, 2016). Introduced by Box and Wilson (1992), SRM consists of a group of mathematical and statistical techniques based on the fit of empirical models to experimental data collected on an experimental design. Linear or square polynomial functions are applied to describe the studied system and then modeling and displacement are used to explore the experimental conditions until they are optimized (Bezerra et al., 2008). After the initial experimental stage, the experiment generally needs to be displaced to an adequate region or a more detailed exploration made of the region to increase the desired response variable (Humberto and de la Vara, 2003; Zhao et al., 2014; Zhu et al., 2014). SRM can be used to evaluate effects in many factors and their interactions in one or more response variables (Myers et al., 2004). One of its advantages is the ability to consider interactions between different variables, consequently reducing the number of experiments needed to produce a mathematical model that can help to predict the behavior of the dependent variables with respect to the independent variables (Guan and Yao, 2008; Karacabey and Mazza, 2010; Prasad et al., 2011; Wang et al., 2012). It is often applied to optimize efficiency in plant tissue culture processes and responses; for example, to optimize callus production and shoot regeneration in Glycine max (Abbasi et al., 2016). In other studies, RSM has been used to optimize the interaction between $\mathrm{pH}$ and sucrose in Mucuna pruriens callus culture (Sundaram et al., 2013), or to define the required mineral nutrients for micropropagation of $C$. avellana cultivars (Hand et al., 2014). Its methodology has also been shown to be very useful in optimizing PGR to improve shoot multiplication in B. polystachyon (Chakraborty et al., 2010) and Lactuca sativa (Gómez-Montes et al., 2015). A RSM system was also applied to improve efficiency for in vitro propagation and regeneration of Ziziphus jujuba Mill (Hou et al., 2018).

The present study objective was to optimize in vitro adventitious shoot induction in $J$. curcas by using RSM as a function of the factors 2ip and IAA for use in rapid and massive propagation, genetic transformation studies, polyploidy induction and/or in vitro germplasm conservation.

\section{Materials and Methods:- \\ Protocol for plant production from adventitious shoot organogenesis of $J$. curcas Explant establishment}

Jatropha curcas seeds were collected from a plantation in Sierra Papacal, Yucatan, Mexico. These were superficially sterilized with $0.5 \%$ benzalkonium chloride (Degasa, México, D.F.), submerged in $1 \%$ Extran ${ }^{\circledR}$ (Hyclin-Plus, México, D.F.) for 15 minutes and dried on absorbent paper for 30 minutes. The seed cover was removed to extract the embryos which were disinfected in a laminar flow cabinet (ESCO, Singapur). Embryos disinfection was done by submerging them in a 5\% Extran ${ }^{\circledR}$ solution for 5 minutes, transferring them to $70 \%$ ethanol for 1 minute, placing them in 30\% sodium hypochlorite (Reactivos CIVEQ, Iztapalapa, México) for 15 minutes and finally rinsing them three times with sterile distilled water. The disinfected embryos were transferred to a magenta GA-7 Vessel (Sigma-Aldrich, Saint Louis, Missouri, Unite State) containing $40 \mathrm{~mL}$ MS medium at $100 \%$ ionic strength, and incubating them at room temperature $\left(23 \pm 2{ }^{\circ} \mathrm{C}\right)$ and $60 \%$ relative humidity $(\mathrm{RH})$ in darkness for fifteen days. Germinated embryos were transferred to a $16 / 8 \mathrm{~h}$ (light/dark) photoperiod with light provided by lightemitting diode (LED) lamps (Manufacturer, Trading Company, China) ( $60 \mu \mathrm{mol}^{-2} \mathrm{~s}^{-1}$ luminous intensity). 


\section{Callogenesis and adventitious shoot induction from explants}

After 15 days of in vitro plant development, $1 \mathrm{~cm}^{2}$ portions of cotyledonal leaves were cut to provide an explant resource. A previous assay was run to identify the factors that have the greatest influence on variable response. These were done in MS medium (Sigma-Aldrich, Saint Louis, Missouri, Unite State) at $75 \%$ ionic strength and containing $282.34 \mu \mathrm{M}$ AdS, $22.5 \%$ sucrose (w/v) and $0.2 \%$ Gelrite (w/v); different concentrations of 2ip, IAA and Adenine sulfate (AdS) were tested.

\section{Adventitious shoot elongation and rooting}

Adventitious shoots cultured for 45 days (1 cm long) were transferred to MS medium at $100 \%$ ionic strength containing $543 \mu \mathrm{M}$ AdS, $4.4 \mu \mathrm{M}$ benzylaminopurine (BAP), $1 \mu \mathrm{M}$ IAA, $22.5 \%$ sucrose (w/v) and $0.3 \%$ Gelrite $(\mathrm{w} / \mathrm{v})$. For rooting, elongated shoots up to $2 \mathrm{~cm}$ long length were cultured in MS medium at $50 \%$ ionic strength containing $20.7 \mu \mathrm{M}$ indolbutiric acid (IBA) (Sigma-Aldrich, Saint Louis, Missouri, Unite State), 22.5\% sucrose (w/v) (Sigma-Aldrich, Saint Louis, Missouri, Unite State) and 0.3\% Gelrite (w/v) (Sigma-Aldrich, Saint Louis, Missouri, Unite State). Culture conditions for elongation and rooting were $23 \pm 2{ }^{\circ} \mathrm{C}, 60 \% \mathrm{RH}$ and a $16 / 8 \mathrm{~h}$ (light/dark) photoperiod; light was provided by light-emitting diode (LED) lamps ( $60 \mu \mathrm{mol}^{-2} \mathrm{~s}^{-1}$ luminous intensity).

\section{Acclimatization}

Pots $(90$ x 80 x $70 \mathrm{~mm}$ ) (MATEC, Morelia, México) were filled with expanded perlite rock (Accimin, Tlalnepantla, México) moistened with tap water. Thirty plantlets with roots were selected and rinsed with tap water to remove excess medium from the roots. Before transplanting, any leaves were removed from the plantlets to avoid dehydration and death. Once transplanted into the pots the plantlets were fumigated with $1 \mathrm{mg} \cdot \mathrm{L}^{-1} \mathrm{copper}$ oxychloride (w/v) (VITA, México, D.F., México), fertilized with bat manure (NPK-10:3:1) (Carmich, Michoacán, México) and covered with transparent nylon bags (Productos de polietileno, Mérida, México) with small holes. Plantlets were cultured in a greenhouse at $30-20 \pm 2{ }^{\circ} \mathrm{C}$ max-min temperature, $70 \% \mathrm{HR}$ and $11 / 13 \mathrm{~h}$ (light/dark) average photoperiod. After seven days the nylon cover was removed, the plantlets watered with distilled water, and bat manure (NPK-10:3:1) added. For the following month and a half, watering was done every other day, fertilizing once a week, and fumigating ( $1 \mathrm{mg} \cdot \mathrm{L}^{-1}$ copper oxychloride) once a week. Total greenhouse culture period was 60 days.

\section{Optimization of adventitious shoot induction \\ Central composite design}

Previous assays of adventitious shoot induction found a combination of cytokinin and auxin to produce the best response, so the central composite design was established using these phytohormones. Embryo establishment was repeated to produce cotyledonal leaves as an explant resource. A $2^{2}$ factorial design with four central points was implemented in which the plant growth regulators 2ip and IAA were the factors to be optimized. The explants were cultured under different treatments (Table 1) in MS medium at 75\% ionic strength containing $282.34 \mu \mathrm{M}$ Adenine sulfate (AdS) (Sigma-Aldrich, Saint Louis, Missouri, Unite State), $22.5 \%$ sucrose (w/v) and $0.2 \%$ Gelrite (w/v).

Table 1:- Variables for central composite design in induction of $\mathrm{J}$. curcas adventitious shoots.

\begin{tabular}{|c|c|c|c|c|c|}
\hline \multirow{2}{*}{ Design } & \multirow{2}{*}{ Treatment number } & \multicolumn{2}{|c|}{ Encoded variable } & \multicolumn{2}{|c|}{ Real variable } \\
\cline { 2 - 6 } & & $\mathbf{X}_{\mathbf{1}}$ & $\mathbf{X}_{\mathbf{2}}$ & $\mathbf{2 i p}(\boldsymbol{\mu M})$ & $\mathbf{I A A}(\boldsymbol{\mu M})$ \\
\hline \multirow{4}{*}{ First } & 1 & - & - & 050 & 1.2 \\
\cline { 2 - 6 } & 2 & + & - & 050 & 1.2 \\
\cline { 2 - 6 } & 3 & - & + & 100 & 1.4 \\
\cline { 2 - 6 } & 4 & 0 & 0 & 075 & 1.3 \\
\cline { 2 - 6 } & 5 & 0 & 0 & 075 & 1.3 \\
\cline { 2 - 6 } & 6 & 0 & 0 & 075 & 1.3 \\
\hline
\end{tabular}

1-4 factorial treatments, 5-8 central point treatments; $2 \mathrm{ip}: 6-(\gamma, \gamma$-Dimethylallylamino $)$ purine; IAA: indolacetic acid.

\section{Rotatable design}


The rotatable design experiments were done after analyzing the central composite design experiment and proving that it fit a second grade model. In this second experiment, the amounts of 2ip and IAA to be used were calculated with the formula:

Isolating the variable $\mathrm{X}_{1}^{\prime}$ :

$$
\sqrt{\mathrm{X} 1} *=\frac{\left(\mathrm{X}_{1}^{\prime}-\mathrm{CP}\right)}{\Delta}
$$

$$
\mathrm{X}_{1}^{\prime}=\mathrm{CP}+\Delta(\sqrt{\mathrm{X}} 1 *)
$$

Where $\mathrm{X}_{1}^{\prime}=$ real value to attain in each variable; $\sqrt{\mathrm{X}} 1 *=\operatorname{coded}$ variable replaced by $-\sqrt{2}$ or $\sqrt{2} ; \mathrm{CP}=$ central point of the variable range; and $\Delta=$ increase of range to the central point.

For this experiment (Table 2), cotyledonal leaf explants were placed in MS medium at $75 \%$ ionic strength containing $282.34 \mu \mathrm{M}$ AdS, $22.5 \%$ sucrose (w/v) and $0.2 \%$ Gelrite (w/v).

\begin{tabular}{|c|c|c|c|c|c|}
\hline & \multirow[t]{2}{*}{ Treatment number } & \multicolumn{2}{|c|}{ Encoded variable } & \multicolumn{2}{|c|}{ Real variable } \\
\hline & & & & 2ip & IAA \\
\hline DESIGN & & $\mathrm{X} 1$ & $\mathrm{X} 2$ & $\mu \mathrm{M}$ & $\mu \mathrm{M}$ \\
\hline \multirow{4}{*}{ Second } & 9 & $+\sqrt{2}$ & 0 & 110.4 & 1.3 \\
\hline & 10 & $-\sqrt{2}$ & 0 & 39.65 & 1.3 \\
\hline & 11 & 0 & $+\sqrt{2}$ & 75.00 & 1.4 \\
\hline & 12 & 0 & $-\sqrt{2}$ & 75.00 & 1.1 \\
\hline
\end{tabular}

Table 2:- Second experimental design for optimization of induction of J. curcas adventitious shoots.

9-12 rotatable treatments

\section{Results validation}

Once the second order model and optimum values were obtained, an experiment based on those results were established and analyzed in order to verify and calculate the error percentage of the model.

\section{Experimental development}

The first experimental stage was the central composite design using a $2^{2}$ factorial design with four central points and five replicates. The second stage was the rotatable treatments with four treatments and five replicates. The results validation was a treatment with ten replicates realized three times. Average shoot number per treatment was evaluated in all experiments. The experimental unit was one explant from J. curcas cotyledonal leaves per flask. All data were processed to fit them for quadratic behavior, produce the response surface and then graph the contours. Processing was done with the Statgraphics Centurion XVI software (Statgraphics Technologies, Inc. The Plains, Virginia, URL: http://www.statgraphics.com/).

\section{Results and Discussion:-}

\section{J. curcas Micropropagation}

The J. curcas cotyledonal leaf explants exhibited a $100 \%$ response rate in the formulated medium (Figure 1). At 45 days the shoots had elongated to approximately $2 \mathrm{~cm}$ in length with an average of $15 \pm 3$ roots developed per plant. Survival rate of acclimated plants was $90 \%$. 


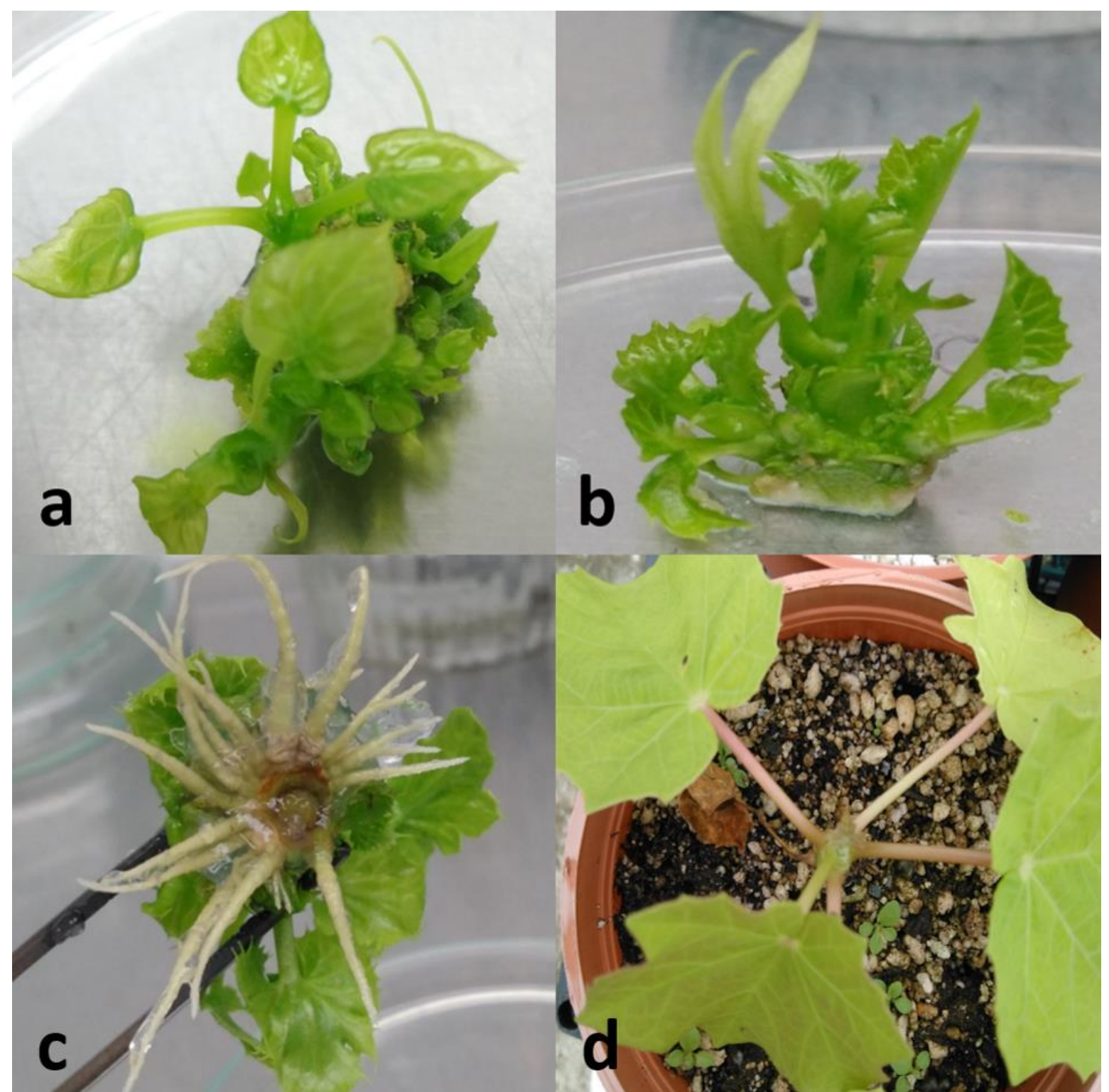

Figure 1:- Micropropagation of J. curcas. a) Adventitious shoots from cotyledonal leaf explants at 45 days; b) elongated adventitious shoots $(2 \pm 0.5 \mathrm{~cm}$ long $)$; c) plantlet roots; and d) acclimated plantlets in greenhouse at 60 days.

Composite central design

In the Pareto diagrams for the previous assays (Figure 2a), the lowest 2ip level is the factor with the highest standardized effect on adventitious shoot induction. A triple interaction near the standardized effect can be observed. The IAA factor had no effect on the response variable. This contrasts with reports that auxin-cytokinin interactions are indispensable because they form a system that controls many aspects in differentiation and cellular development (Coenen and Lomax, 1997). Neither did AdS have an effect on the response variable. This organic compound is reported to have a synergic effect with other cytokinins (Raha and Roy, 2001), and is also a nitrogen source (Husain et al., 2006). It can therefore stimulate cell growth and improve shoot induction, as demonstrated in a study using $135.7 \mu \mathrm{M}$ AdS in which 10.0 1.30 shoots per J. curcas leaf explant were produced (Shrivastava and Banerjee 2008); given this kind of response AdS should not be removed from the central composite design. In the central composite design diagram (Figure 2b), there is a double interaction with 2ip-IAA which surpasses the standardized effect. 

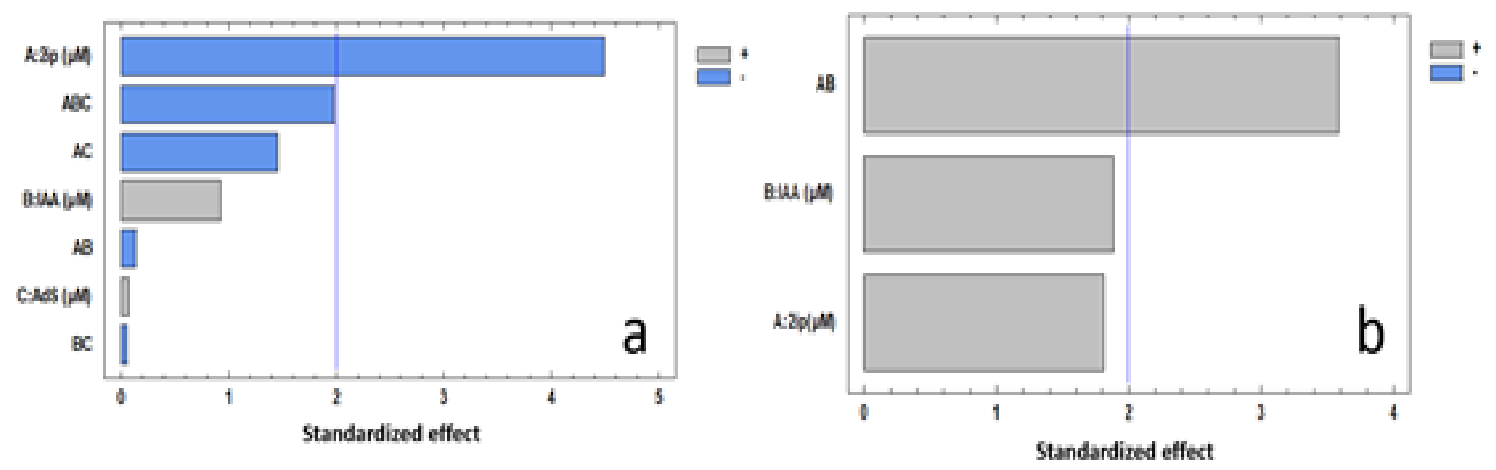

Figure 2:- Pareto diagrams for the 2ip, IAA and AdS factors effect on J. curcas adventitious shoot induction. a) Diagram for previous assays; b) diagram for central composite design $\left(2^{2}\right.$ with four central points).

Fit to quadratic model and response surface analysis

When fitted to the quadratic model the $2^{2}$ central composite design with rotatable treatments was shown to fit to a second order model $(\mathrm{P}<0.05)$, demonstrating that this model had curvature. The adjusted determination coefficient was $85.1 \%$, indicating that the model explains the data. The resulting equation is:

$$
Y=-173.726+0.252628 X_{1}+274.831 X_{2}+0.08 X_{1} X_{2}-0.00216001 X_{1}^{2}-105.001 X_{2}^{2}
$$

The modeled surface for this design was maximum points (Figure 3a); lowest average number of shoots is indicated in blue tones and highest average number in red-orange tones. This surface occurred with the combination of $83 \mu \mathrm{M}$ 2ip and $1.3 \mu \mathrm{M}$ IAA. In the maximum points response contour graphic (Figure $3 \mathrm{~b}$ ), the maximum number of shoots obtained was 21. In the same graphic the highest effect factor is IAA, suggesting broad changes in concentrations can easily change the response variable. This agrees with the fact that PGR are organic substances that quickly and effectively influence physiologic processes when applied in low, specific concentrations (Davies, 2010).
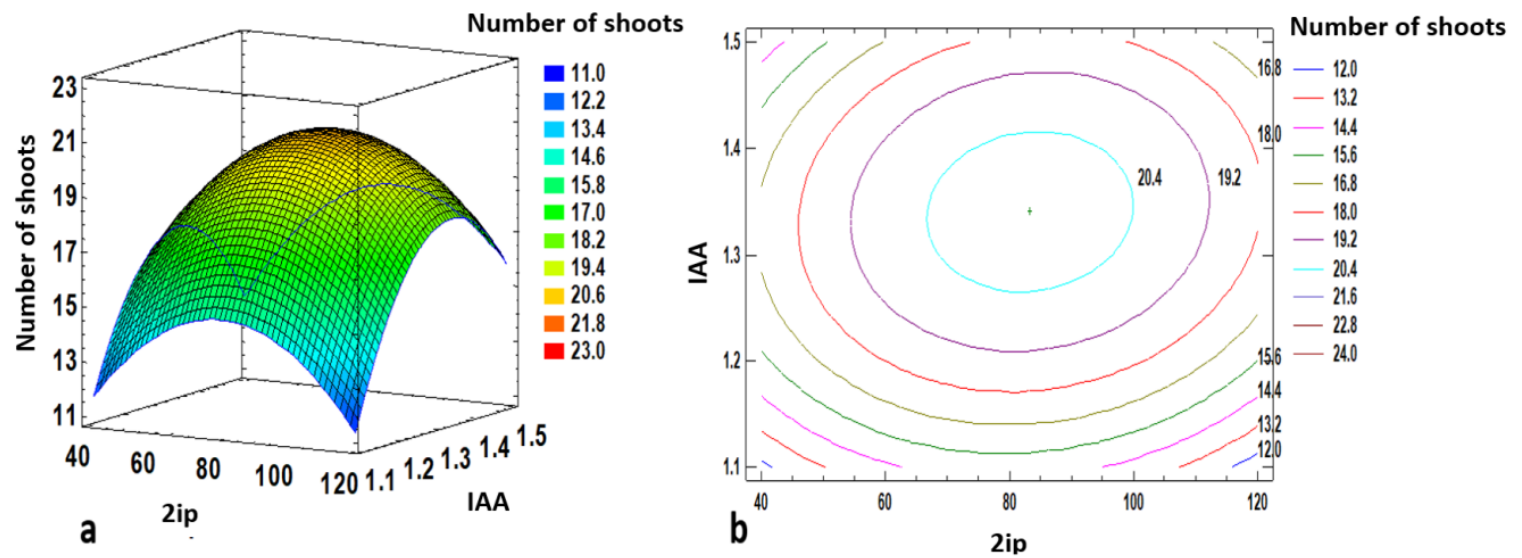

Figure 3:- Response surface generated for optimization of in vitro adventitious shoot induction in J. curcas. a) Maximum points surface, b) Contour graphic.

Application of exogenous IAA auxin is generally required to achieve rooting (Diaz-Sala et al., 1996), although 2.85 $\mu \mathrm{M}$ auxin has been used in combination with BAP cytokinin to produce adventitious shoots in J. curcas (Rajore and Batra, 2005). Combining an auxin with a cytokinin is indispensable for shoot induction, but depends on which PGR is added to the medium. For example, in a study of induction using $14.7 \mu \mathrm{M}$ 2ip in combination with different auxins, only white and green compact calluses and light yellowish and soft friable calluses were produced (Kaewpoo and Te-chato, 2009). In the present results, by contrast, IAA auxin in combination with 2ip supported adventitious shoot induction. The 2ip cytokinin is a precursor of zeatin synthesis (Miura and Miller, 1969), and is widely used in plant tissue culture. It is also a PGR with important roles in shoot bud induction and elongation (Shibil et al., 2017), 
and development of microshoots and shoot multiplication (Tahtamouni et al., 2017). The average 2ip concentration used for J. curcas shoot induction has ranged from 2.5 to $39.4 \mu \mathrm{M}$, which produced $1.2 \pm 0.05$ shoots per nodal explant (Datta et al., 2007), to 1 and $7.5 \mu \mathrm{M}$ 2ip, which produced 2.7 shoots per explant (Purkayastha et al., 2010). In both cases only $2 \mathrm{ip}$ was used for shoot induction. However, addition of IAA auxin can notably increase induction, as shown in the response surface generated here (Figure 3). Indeed, this is the first report on how IAA and 2ip in combination support adventitious shoot induction in J. curcas. Most PGR exhibit different modes of action on different species or varieties. For example, in Juncus effuses no significant differences were observed between BAP and $2 \mathrm{iP}$ in a comparison of regeneration responses, although $2 \mathrm{iP}$ did induce the highest number of shoots (Sarma and Rogers, 2000). Continued evaluation of interactions between 2ip and IAA could help to further increase shoot number induction in J. curcas.

Previous reports on adventitious shoot induction in $\mathrm{J}$. curcas have used different concentrations of PGR such as thidiazuron (TDZ), 6-benzylaminopurine (BAP), 3-indolacetic acid (IAA), gibberellic acid (GA 3 ), kinetin (Kin), and 2,4-dichlorophenoxyacetic acid (2,4-D). These resulted in induction of up to seven adventitious shoots per explant from petiole leaves (Liu et al., 2015), eleven per leaf explant (Verma and Verma, 2015), and thirteen from cotyledonal leaf explants (Liu et al., 2016). In contrast, application of an RSM in the present study to optimize adventitious shoot induction in J. curcas demonstrated that 21 adventitious shoots per explant can be generated using a combination of MS medium at $75 \%$ ionic strength, $83.3 \mu \mathrm{M}$ 2ip and $1.3 \mu \mathrm{M}$ IAA.

Validation

The validation showed $10.95 \%$ of error as can be seen in Table 3 which the optimum obtained was 21 adventitious shoots and validation was 18.7 adventitious shoot buds. From the RSM model and the optimization results, the predicted and measured values are quite close, which

Indicates that the developed model can be effectively used to predict the surface response in adventitious shoot bud induction.

Table 3:- Error percentage obtained accord to theoretical and practical of adventitious shoot buds.

\begin{tabular}{|c|c|c|c|c|}
\hline \multicolumn{2}{|c|}{ Factors } & Number of adventitious shoot buds obtained & \multirow{2}{*}{ Error percentage $(\%)$} \\
\hline 2ip $(\boldsymbol{\mu M})$ & IAA $(\boldsymbol{\mu M})$ & Theoretical & Practical & \\
\hline 83 & 1.3 & 21 & 19 & 9.5 \\
\hline
\end{tabular}

2ip: 6- $(\gamma, \gamma$-Dimethylallylamino) purine; IAA: indolacetic acid.

\section{Conclusions:-}

This is the first report on optimization of adventitious shoot induction in Jatropha curcas for use in rapid and massive propagation, genetic improvement or in vitro germplasm conservation. The protocol described here is efficient for indirect organogenesis through cotyledonal leaf explants, and a second order model was produced to predict the effect of $2 \mathrm{ip}$ and IAA on adventitious shoot induction in Jatropha curcas.

\section{Acknowledgment:-}

The research reported here was financed by the SAGARPA-CONACYT Fund through a grant (project 2011163502). GJHC received a Ph.D. scholarship from the Consejo Nacional de Ciencia y Tecnología (CONACyT) (No. 266749/218511).

\section{References:-}

1. Abbasi, Z., Hooshyar, S., Bagherieh-Najjar, M. B. (2016): Improvement of callus production and shoot regeneration using various organs of soybean (Glycine max L. Merr) by response surface methodology. In Vitro Cellular \& Developmental Biology-Plant 52:537-545.

2. Anderson, M.J., Whitcomb, P. J. (2016): RSM simplified: optimizing processes using response surface methods for design of experiments. Productivity Press. Miami, Florida, pp 53-63.

3. Bezerra, M. A., Santelli, R. E., Oliveira, E. P., Villar, L.S., Escaleira, L. A. (2008): Response surface methodology (RSM) as a tool for optimization in analytical chemistry. Talanta 76:965-977.

4. Box, G. E., Wilson, K. B. (1992): On the experimental attainment of optimum conditions. In Breakthroughs in Statistics, Springer, New York, pp 270-310. 
5. Chakraborty, D., Bandyopadhyay, A., Bandopadhyay, S., Gupta, K., Chatterjee, A. (2010): Use of response surface methodology for optimization of a shoot regeneration protocol in Basilicum polystachyon. In Vitro Cellular \& Developmental Biology-Plant 46:451-459.

6. Coenen, C., Lomax, T. L. (1997): Auxin-cytokinin interactions in higher plants: old problems and new tools. Trends in Plant Science 2:351-356.

7. Datta, M. M., Mukherjee, P., Ghosh, B., Jha, T. B. (2007): In vitro clonal propagation of biodiesel plant (Jatropha curcas L.). Current Science 93:1438-1442.

8. Davies, P. J. (2010): The plant hormones: their nature, occurrence, and functions. In: Plant hormones, Springer, Dordrecht pp 1-15.

9. Diaz-Sala, C., Hutchison, K. W., Goldfarb, B., Greenwood, M. S. (1996): Maturation-related loss in rooting competence by loblolly pine stem cuttings: The role of auxin transport, metabolism and tissue sensitivity. Physiologia Plantarum 97:481-490.

10. Gómez-Montes, E. O., Oliver-Salvador, C., Durán-Figueroa, N., Badillo-Corona, J. A., Salas, C. E. (2015): Optimization of direct shoot regeneration using cotyledonary explants and true leaves from lettuce cv. Romaine (Lactuca sativa L.) by surface response methodology. Plant Growth Regulation 77:327-334.

11. Guan, X., Yao, H. (2008): Optimization of Viscozyme L-assisted extraction of oat bran protein using response surface methodology. Food Chemistry 106:345-351.

12. Hand, C., Maki, S., Reed, B. M. (2014): Modeling optimal mineral nutrition for hazelnut micropropagation. Plant Cell Tissue and Organ Culture 119:411-425.

13. Hou, L., Wang, Y., Cui, Y., Pang, X., Li, Y. (2018): Optimization of a highly efficient shoot regeneration system using leaf explants of Chinese jujube (Ziziphus jujuba Mill.) by response surface methodology. The Journal of Horticultural Science and Biotechnology 93:289-295.

14. Humberto, G.P., de la Vara, S. R. (2003): Análisis y Diseño de Experimentos. McGraw Hill. México, D.F. pp 346-367.

15. Husain, M. K., Anis, M., Shahzad, A. (2006): In vitro control of shoot tip necrosis (STN) in Pterocarpus marsupium Roxb.-a leguminous tree. Physiol and Molecular Biol of Plants 12:259-301.

16. Karacabey, E., Mazza, G. (2010): Optimization of antioxidant activity of grape cane extracts using response surface methodology. Food Chemistry 119:343-348.

17. Li, C. A., Xie, L., Mao, H., Qiu, C., Srinivasan, R., Hong, Y. (2016): Engineering low phorbol ester Jatropha curcas seed by intercepting casbene biosynthesis. Plant Cell Reports 35:103-114.

18. Liu, Y., Lu, J., Zhu, H., Li, L., Shi, Y., Yin, X. (2016): Efficient culture protocol for plant regeneration from cotyledonary petiole explants of Jatropha curcas L. Biotechnology and Biotechnological Equipment 30: 907914.

19. Liu, Y., Tong, X., Hui, W., Liu, T., Chen, X., Li, J., Liu, Z. (2015): Efficient culture protocol for plant regeneration from petiole explants of physiologically mature trees of Jatropha curcas L. Biotechnology and Biotechnological Equipment 29:479-488.

20. Miura, G. A., Miller, C. O. (1969): 6- $(\gamma, \gamma$-Dimethylallylamino) purine as a precursor of zeatin. Plant Physiology 44:372-376.

21. Miller, C. O., Skoog, F., Okumura, F. S., Von Saltza, M. H., Strong, F. M. (1956): Isolation, structure and synthesis of kinetin, a substance promoting cell division1, 2. Journal of the American Chemical Society 78:1375-1380.

22. Mok, M. C. (1994): Cytokinins and plant development. Cytokinins: chemistry, activity and function. Oregon, Unite State, pp 155-166.

23. Murashige, T., Skoog, F. (1962): A revised medium for rapid growth and bioassays with tobacco tissue cultures. Physiologia Plantarum 15:473-497.

24. Myers, R. H., Montgomery, D. C., Vining, G. G., Borror, C. M., Kowalski, S. M. (2004): Response surface methodology: a retrospective and literature survey. Journal of quality technology 36:53-77.

25. Navarro, P. F. S., Baz, R. S. A., Handler, R., Sacramento, R. J. (2016): Advances on the processing of Jatropha curcas towards a whole-crop biorefinery. Renewable and sustainable. Energy Reviews 54:247-269.

26. Panghal, S., Beniwal, V. S., Laura, J. S. (2012): An efficient plant regeneration protocol from petiole explants of physic nut (Jatropha curcas L.). African Journal of Biotechnology 11:12652-12656.

27. Prasad, K. N., Hassan, F. A., Yang, B., Kong, K. W., Ramanan, R. N., Azlan, A., Ismail, A. (2011): Response surface optimization for the extraction of phenolic compounds and antioxidant capacities of underutilised Mangifera pajang Kosterm peels. Food Chemistry 128:1121-1127.

28. Raha, S., Roy, S. C. (2001): In vitro plant regeneration in Holarrhena antidysenterica wall through highfrequency axillary shoots proliferation. In Vitro Cellular \& Developmental Biology-Plant 37:232-236. 
29. Rajore, S., Batra, A. (2005): Efficient plant regeneration via shoot tip explant in Jatropha curcas L. Journal of Plant Biochemistry and Biotechnology 14:73-75.

30. Sarma, K. S., Rogers, S. M. D. (2000): Plant regeneration from seedling explants of Juncus effusus. Aquatic Botany 68:239-247.

31. Shibli, R. A., Sharaf, S. A., Kasrawi, M. A., Al-Qudah, T. S. (2018): In Vitro Multiplication of the White Wormwood, Artemisia herba-alba asso. Jordan Journal of Biological Sciences 11:265-271.

32. Shrivastava, S., Banerjee, M. (2008): In vitro clonal propagation of physic nut (Jatropha curcas L.): Influence of additives. Int. J. Integr. Biol 3:73-77.

33. Soares, D. M., Sattler, M. C., da Silva Ferreira, M. F., Praça, F. M. (2016): Assessment of Genetic Stability in Three Generations of in vitro Propagated Jatropha curcas L. Plantlets Using ISSR Markers. Tropical Plant Biology 9:229-238.

34. Sujatha, M., Makkar, H. P. S., Becker K (2005): Shoot bud proliferation from axillary nodes and leaf sections of non-toxic Jatropha curcas L. Plant Growth Regulation 47:83-90.

35. Sundaram, U., Anupama, V., Gurumoorthi, P. (2013): Optimization of $\mathrm{pH}$ and sucrose in the callus culture for the micropropagation of Mucuna pruriens using response surface methodology. Int J Pharm Pharmaceut Sci 5:420-426.

36. Tahtamouni, R. W., Shibli, R. A., Younes, L. S. (2017): In Vitro Propagation, Direct Regeneration and Acclimatization of Solanum villosum (L.) Mill.: A Promising Medicinal Plant That Grows Wild In Jordan. Jordan Journal of Agricultural Sciences 13:65-78.

37. Teale, W. D., Paponov, I. A., Palme, K. (2006): Auxin in action: signalling, transport and the control of plant growth and development. Nature Reviews Molecular Cell Biology 7:847-859.

38. Verma, K. C., Verma, S. K. (2015): Interaction effect of explants types and phytohormones on tissue culture of Jatropha curcas seed embryo. Interaction 10:563-566.

39. Wang, H., Liu, Y., Wei, S., Yan, Z. (2012): Application of response surface methodology to optimize supercritical carbon dioxide extraction of essential oil from Cyperus rotundus Linn. Food Chemistry 132:582587.

40. Werner, T., Motyka, V., Laucou, V., Smets, R., Van Onckelen, H., Schmülling, T. (2003): Cytokinin-deficient transgenic Arabidopsis plants show multiple developmental alterations indicating opposite functions of cytokinins in the regulation of shoot and root meristem activity. The Plant Cell 15:2532-2550.

41. Zhang, C., Fu, S., Tang, G., Hu, X., Guo, J. (2013): Factors influencing direct shoot regeneration from mature leaves of Jatropha curcas, an important biofuel plant. In Vitro Cellular \& Developmental Biology-Plant 49:529540.

42. Zhao, X., Han, Y., Tan, X. Q., Wang, J., Zhou, Z. J. (2014): Optimization of antifungal lipopeptide production from Bacillus sp. BH072 by response surface methodology. Journal of Microbiology 52:324-332.

43. Zhu, X., Mang, Y., Shen, F., Xie, J., Su, W. (2014): Homogenate extraction of gardenia yellow pigment from Gardenia jasminoides Ellis fruit using response surface methodology. Journal of Food Science and Technology 51:1575-1581. 